\title{
Factors affecting local regrowth after watch and wait for patients with a clinical complete response following chemoradiotherapy in rectal cancer (InterCoRe consortium)
}

\author{
Citation for published version (APA): \\ Chadi, S. A., Malcomson, L., Ensor, J., Riley, R. D., Vaccaro, C. A., Rossi, G. L., Daniels, I. R., Smart, N. \\ J., Osborne, M. E., Beets, G. L., Maas, M., Bitterman, D. S., Du, K., Gollins, S., Myint, A. S., Smith, F. M., \\ Saunders, M. P., Scott, N., O'Dwyer, S. T., ... Renehan, A. G. (2018). Factors affecting local regrowth \\ after watch and wait for patients with a clinical complete response following chemoradiotherapy in rectal \\ cancer (InterCoRe consortium): an individual participant data meta-analysis. The Lancet Gastroenterology \\ and Hepatology, 3(12), 825-836. https://doi.org/10.1016/S2468-1253(18)30301-7
}

\section{Document status and date: \\ Published: 01/12/2018}

DOI:

10.1016/S2468-1253(18)30301-7

Document Version:

Publisher's PDF, also known as Version of record

\section{Document license:}

Taverne

\section{Please check the document version of this publication:}

- A submitted manuscript is the version of the article upon submission and before peer-review. There can be important differences between the submitted version and the official published version of record. People interested in the research are advised to contact the author for the final version of the publication, or visit the DOI to the publisher's website.

- The final author version and the galley proof are versions of the publication after peer review.

- The final published version features the final layout of the paper including the volume, issue and page numbers.

Link to publication

\footnotetext{
General rights rights.

- You may freely distribute the URL identifying the publication in the public portal. please follow below link for the End User Agreement:

www.umlib.nl/taverne-license

Take down policy

If you believe that this document breaches copyright please contact us at:

repository@maastrichtuniversity.nl

providing details and we will investigate your claim.
}

Copyright and moral rights for the publications made accessible in the public portal are retained by the authors and/or other copyright owners and it is a condition of accessing publications that users recognise and abide by the legal requirements associated with these

- Users may download and print one copy of any publication from the public portal for the purpose of private study or research.

- You may not further distribute the material or use it for any profit-making activity or commercial gain

If the publication is distributed under the terms of Article 25fa of the Dutch Copyright Act, indicated by the "Taverne" license above, 


\title{
Factors affecting local regrowth after watch and wait for patients with a clinical complete response following chemoradiotherapy in rectal cancer (InterCoRe consortium): an individual participant data meta-analysis
}

\author{
Sami A Chadi, Lee Malcomson, Joie Ensor, Richard D Riley, Carlos A Vaccaro, Gustavo L Rossi, Ian R Daniels, Neil J Smart, Melanie E Osborne, \\ Geerard L Beets, Monique Maas, Danielle S Bitterman, Kevin Du, Simon Gollins, Arthur Sun Myint, Fraser M Smith, Mark P Saunders, Nigel Scott, \\ Sarah T O'Dwyer, Rodrigo Otavio de Castro Araujo, Marcus Valadao, Alberto Lopes, Cheng-Wen Hsiao, Chien-Liang Lai, Radhika K Smith, \\ Emily Carter Paulson, Ane Appelt, Anders Jakobsen, Steven D Wexner, Angelita Habr-Gama, Guilherme Sao Julião, Rodrigo O Perez, \\ Andrew $G$ Renehan
}

\section{Summary}

Background In patients with rectal cancer who achieve clinical complete response after neoadjuvant chemoradiotherapy, watch and wait is a novel management strategy with potential to avoid major surgery. Study-level meta-analyses have reported wide variation in the proportion of patients with local regrowth. We did an individual participant data metaanalysis to investigate factors affecting occurrence of local regrowth.

Methods We updated search results of a recent systematic review by searching MEDLINE and Embase from Jan 1, 2016, to May 5, 2017, and used expert knowledge to identify published studies reporting on local regrowth in patients with rectal cancer managed by watch and wait after clinical complete response to neoadjuvant chemoradiotherapy. We restricted studies to those that defined clinical complete response using criteria equivalent to São Paulo benchmarks (ie, absence of residual ulceration, stenosis, or mass within the rectum on clinical and endoscopic examination). The primary outcome was 2-year cumulative incidence of local regrowth, estimated with a two-stage random-effects individual participant data meta-analysis. We assessed the effects of clinical and treatment factors using Cox frailty models, expressed as hazard ratios (HRs). From these models, we derived percentage differences in mean $\theta$ as an approximation of the effect of measured covariates on between-centre heterogeneity. This study is registered with PROSPERO, number CRD42017070934.

Findings We obtained individual participant data from 11 studies, including 602 patients enrolled between March 11, 1990, and Feb 13, 2017, with a median follow-up of 37.6 months (IQR 25.0-58.7). Ten of the 11 datasets were judged to be at low risk of bias. 2-year cumulative incidence of local regrowth was $21.4 \%$ (random-effects $95 \% \mathrm{CI}$ 15.3-27-6), with high levels of between-study heterogeneity $\left(I^{2}=61 \%\right)$. We noted wide between-centre variation in patient, tumour, and treatment characteristics. We found some evidence that increasing $\mathrm{cT}$ stage was associated with increased risk of local regrowth (random-effects HR per cT stage 1.40, 95\% CI 1.00-1.94; $p_{\text {trend }}=0$. 048). In a subgroup of 459 patients managed after 2008 (when pretreatment staging by MRI became standard), 2-year cumulative incidence of local regrowth was $19 \%$ (95\% CI 13-28) for stage cT1 and cT2 tumours, 31\% (26-37) for cT3, and $37 \%$ (21-60) for cT4 (random-effects HR per cT stage 1.50, random-effects 95\% CI 1.03-2.17; $\mathbf{p}_{\text {trend }}=\mathbf{0} \cdot \mathbf{0 3 3 0}$ ). We estimated that measured factors contributed $4 \cdot 8-45 \cdot 3 \%$ of observed between-centre heterogeneity.

Interpretation In patients with rectal cancer and clinical complete response after chemoradiotherapy managed by watch and wait, we found some evidence that increasing $\mathrm{cT}$ stage predicts for local regrowth. These data will inform clinician-patient decision making in this setting. Research is needed to determine other predictors of a sustained clinical complete response.

Funding None.

Copyright (c) 2018 Elsevier Ltd. All rights reserved.

\section{Introduction}

Surgical resection is the mainstay of treatment for rectal cancer. ${ }^{1}$ In patients who receive preoperative neoadjuvant chemoradiotherapy, up to a quarter have complete tumour regression, recognisable as a clinical complete response. ${ }^{2}$ In these patients, a watch-and-wait management strategy allows some patients to safely avoid major pelvic surgery. ${ }^{3}$ This strategy originated from studies ${ }^{46}$ done in São Paulo, Brazil, more than a decade ago, and has been extended, for example, to a large series of patients in the Netherlands ${ }^{7.8}$ and to a multicentre network in the northwest of England and Wales (the OnCoRe
Lancet Gastroenterol Hepato 2018; 3: 825-36 Published Online October 11, 2018 http://dx.doi.org/10.1016/ S2468-1253(18)30301-7

This online publication has been corrected. The corrected version first appeared at thelancet.com/gastrohep on January 8, 2018

See Comment page 814

Division of Surgical Oncology and General Surgery, Princess Margaret Hospital and University Health Network, University of Toronto, Toronto, ON, Canada (S A Chadi MD) Manchester Cancer Research Centre and NIHR Manchester Biomedical Research Centre, Division of Cancer Sciences, School of Medical Sciences, Faculty of Biology, Medicine and Health, University of Manchester, Manchester, UK (L Malcomson BSc); Colorectal and Peritoneal Oncology Centre (L Malcomson, Prof ST O'DwyerMD, Prof A G Renehan PhD), and Department of Clinical Oncology

(Prof M P Saunders PhD), The Christie NHS Foundation Trust Manchester, UK; Centre for Prognosis Research, Research Institute for Primary Care and Health Sciences, Keele University, Staffordshire, UK (J Ensor PhD, Prof R D Riley PhD, A G Renehan); Servicio Cirugia General, Sector de

Coloproctologia, Hospital Italiano de Buenos Aires, Buenos Aires, Argentina (CA Vaccaro PhD, G L Rossi MD), Exeter Colorectal Unit, and Exeter Surgical Health Sciences Research Unit (HESRU), Royal Devon and Exeter NHS 
Foundation Trust, Exeter, Devon, UK (I R Daniels MD, NJ Smart PhD,

M E Osborne FRCR); Department of Surgery, Netherlands Cancer Institute, Amsterdam, Netherlands

(Prof G L Beets PhD); GROW, School of Oncology and Developmental Biology, University of Maastricht,

Maastricht, Netherlands (Prof G L Beets); Department of Radiology, Netherlands Cancer Institute, Amsterdam, Netherlands (M Maas PhD); Harvard Radiation Oncology Program, Boston, MA, USA (D S Bitterman MD); Department of Radiation Oncology, New York University Langone Medical Center, New York, NY, USA (K Du PhD); North Wales Cancer Treatment Centre, Rhyl, UK (S Gollins DPhil); Clatterbridge Cancer Centre, Liverpool, UK (Prof A Sun Myint FRCR); Royal Liverpool Hospital NHS Foundation Trust, Liverpool,

UK (F M Smith MD); Royal Preston NHS Foundation Trust, Preston, UK (N Scott MD); Department of Abdominal and Pelvic Surgery, Instituto Nacional de Câncer José Alencar Gomes da Silva (INCA), Rio de Janeiro, Brazil (R O de Castro Araujo MD, M Valadao PhD, A Lopes MD); Division of Colon and Rectal Surgery, Department of Surgery, Tri-Service General Hospital, National Defense Medical Center, Taipei, Taiwan, China (C-W Hsiao MD,

C-L Lai MD); Department of Surgery, Philadelphia VA

Medical Center, and Division of

Colon and Rectal Surgery,

Hospital of the University of Pennsylvania, Philadelphia, PA, USA (R K Smith MD,

E (Paulson MD); Danish Colorectal Cancer Center South, Vejle Hospital, Vejle, Denmark (A Appelt PhD,

Prof A Jakobsen DMSc); Leeds Cancer Centre, St James's University Hospital, and Leeds Institute of Cancer and Pathology, University of Leeds, Leeds, UK (A Appelt); Department of Colorectal Surgery, Cleveland Clinic Florida, Weston, FL, USA (Prof S D Wexner PhD); Instituto

Angelita e Joaquim Gama, São Paulo, Brazil (Prof A Habr-Gama MD, R O Perez PhD);
Research in context

\section{Evidence before this study}

In patients with rectal cancer who achieve a complete clinical response after chemoradiotherapy, a watch-and-wait strategy offers patients an opportunity to avoid major resection surgery. However, in the absence of randomised trials, this approach is not standard care. We searched MEDLINE for articles in the English language published from Jan 1, 2004 (the year of the first major São Paulo publication) to Aug 10, 2018. We sought to identify published meta-analyses, pooled analyses, and large-scale registry-based analyses in patients with clinical complete response to neoadjuvant chemoradiotherapy who were managed with a watch-and-wait strategy. Two recently published study-level meta-analyses reported regrowth in $15.7 \%$ of patients at 2 years and $21.6 \%$ of patients at 3 years, respectively. However, both of those studies noted substantial between-study heterogeneity, with a wide range of regrowth rates reported in different studies. A register-based project, the International Watch and Wait Database (IWWD), recently estimated 2-year cumulative incidence of local regrowth at $25.2 \%$ in 880 patients from 47 participating institutions in 15 countries who were managed by watch and wait after clinical complete response. Understanding factors that predict for local regrowth might explain the high levels of between-study heterogeneity in published studies. To date, no large-scale study has investigated predictive factors for local regrowth because of an inability to extract data in an analysable form or because of substantial missing data.

\section{Added value of this study}

To our knowledge, this is the first reported individual participant data meta-analysis to investigate factors affecting local regrowth in patients with rectal cancer managed by watch

project). ${ }^{2}$ In a matched cohort analysis of the OnCoRe data, ${ }^{2}$ survival rates in patients managed by watch and wait were not inferior to those in patients treated by standard surgical resection. Nonetheless, watch and wait has yet to reach universal acceptance in oncology and is not standard care.

In 2017, Dossa and colleagues ${ }^{9}$ reported a study-level meta-analysis of 23 studies (15 published; eight unpublished) including 871 patients, in which they quantified the risk of local tumour regrowth in patients managed by watch and wait in the setting of clinical complete response to neoadjuvant chemotherapy. The proportion of patients with local regrowth at 2 years was $15 \cdot 7 \%$, but the investigators noted substantial between-study heterogeneity $\left(I^{2}=55.9 \%\right)$, with regrowth rates ranging from $3 \cdot 3 \%$ to $33 \cdot 3 \%$. $^{9}$ In a second studylevel meta-analysis ${ }^{10}$ of 17 published studies ( 692 patients), the 3-year cumulative risk of local regrowth was $21.6 \%$, again with high levels of heterogeneity $\left(I^{2}=66 \cdot 5 \%\right)$. Such between-study heterogeneity adds to concerns that watch-and-wait management, practised mostly at and wait after clinical complete response following chemoradiotherapy. The use of individual participant data allowed us to test for predictive factors of local regrowth and, using Cox frailty models, to account for unmeasured factors at the study level, such as centre-level protocols for staging, treatment, and follow-up. We obtained data from 11 studies comprising 602 patients, with a median follow-up of 37.6 months, and we estimated 2-year cumulative incidence of local regrowth at $21.4 \%$. We found some evidence that increasing CT stage was associated with increased risk of local regrowth, an association that remained after adjustments. No associations were found for other predictors, including age, sex, cN stage, distance of tumour from anal verge, serum carcinoembryonic antigen concentration, radiotherapy dose, and time to watch-and-wait decision.

\section{Implications of all the available evidence}

The current literature notes wide variation in the proportion of patients managed by watch and wait who have local tumour regrowth, raising the concern that this strategy might not be generalisable to standard care. Our analysis demonstrated that this variation is partly explained by differences in study baseline characteristics. To our knowledge, this is the first large-scale study to show that increasing CT stage is associated with increased risk of subsequent local regrowth. In a subgroup of patients managed after 2008 (reflecting standard use of pretreatment staging by high-resolution MRI), 2-year cumulative incidence of local regrowth was $19 \%$ for stage $\mathrm{cT} 1$ and cT2 tumours, 31\% for CT3, and 37\% for cT4. These estimates will inform clinicianpatient decision making and future trials in the field of organ preservation in patients with rectal cancer.

specialist centres, might not be generalisable to standard care. Understanding the factors that predict for local regrowth might help to explain the causes of betweenstudy heterogeneity and thus better inform clinical pathways.

We did an individual participant data meta-analysis with data from 11 published studies within the International Complete Response (InterCoRe) consortium, with a central aim to investigate factors affecting local regrowth after clinical complete response to chemotherapy. The InterCoRe project parallels the International Watch and Wait Database (IWWD) project, ${ }^{11}$ which recently reported a 2-year cumulative incidence of local regrowth of $25 \cdot 2 \%$ in 880 patients from 47 participating institutions (15 countries) who had clinical complete response to chemotherapy and were managed by watch and wait.

The individual participant data meta-analysis approach has several advantages over the published study-level meta-analyses ${ }^{9,10}$ and the registry-based IWWD study. ${ }^{11}$ Individual participant data allow one to standardise 
inclusion criteria and analyses, to obtain study results not included in published studies, to check modelling assumptions,$^{12}$ and importantly for this study, to model data as time-to-event cumulative incidence rather than report crude rates. Individual participant data metaanalysis also allows one to model individual-level covariate outcomes directly clustered within studies, and minimises ecological bias. ${ }^{13}$ To date, no large-scale study has assessed predictive factors for local regrowth because of an inability to extract these data in an analysable form $^{9,10}$ or because of substantial missing data. ${ }^{11}$

\section{Methods}

\section{Search strategy and study selection}

This study is reported in accordance with PRISMA-IPD guidelines. ${ }^{14}$ We sought to identify studies of patients with locally advanced rectal cancer where the intervention was watch and wait after clinical complete response to neoadjuvant chemoradiotherapy, as the predominant treatment within each reported study, and followed up to local regrowth, as defined by the 2014 Champalimaud conference. ${ }^{15}$ We anticipated that most studies would be single-arm series without a comparator group.

We used the systematic search published by Dossa and colleagues, ${ }^{9}$ because our PICO (population; intervention; comparator; outcome) was equivalent and updated it by searching MEDLINE and Embase databases. We assessed the studies included in the review from Dossa and colleagues (where the search was up to June 28, 2016); then used their search terms to seek further published studies from Jan 1, 2016, to May 5, 2017; and finally, supplemented this search with studies identified through expert knowledge. ${ }^{9}$ No language restrictions were applied. The search terms are detailed in the appendix (p 1).

Because the aim of the study was to assess predictive factors, we sought to include a more uniform population and therefore only included studies in which the definition of clinical complete response was judged to have used criteria equivalent to those of the São Paulo benchmarks described by Habr-Gama and colleagues in $2004^{5}$ and $2010^{16}$ - namely, absence of residual ulceration, stenosis, or mass within the rectum on clinical and endoscopic examination. Because abstracts did not allow for this assessment, we excluded unpublished studies. Although previous reports using the Habr-Gama definition ${ }^{5,16}$ restricted cases to the distal rectum, subsequent publications, including two large patient series, ${ }^{2,8}$ two meta-analyses, ${ }^{9,10}$ and the IWWD report ${ }^{11}$ included patients with proximal rectal tumours. Thus, we did not restrict by tumour distance from the anal verge.

\section{Data collection and harmonisation}

We approached chief investigators of identified studies and requested transfer of fully anonymised data in encrypted files under centre-level governance arrangements. Data harmonisation is detailed in the appendix (p 2). To ensure homogeneity of patients entering into watch-and-wait management, we excluded patients who received short-course radiotherapy as initial treatment; patients treated by local excision or contact X-ray brachytherapy (Papillon technique) as part of the initial watch-and-wait management; and patients with distant metastases at baseline. Research ethics committees or other entities overseeing the use of patients data had approved the collaborating cohorts. Cohorts shared only anonymised data, so neither individual consent nor specific approval for this individual patient data meta-analysis were required.

\section{Risk of bias assessment in individual studies}

To assess study quality, we modified the Institute of Health Economics Quality Appraisal (IHEQA) checklist for case series studies, ${ }^{17}$ which consists of 18 items (yes or no responses) with explanatory dictionaries. Only the first 11 items were relevant for our analysis because subsequent items relate to reporting qualities, which do not apply to the individual participant data meta-analysis framework. We further modified two items so that yes or intermediate or no responses were permitted. Studies were considered to have a low risk of bias if at least $80 \%$ of criteria were met, moderate risk if $60-79 \%$ of criteria were met, and high risk if less than $60 \%$ of criteria were met.

\section{Outcome measures}

The primary outcome was 2-year cumulative incidence of local regrowth from the date of the watch-and-wait decision, defined here as the date at which clinical complete response was achieved. Secondary outcomes were cumulative incidence of local regrowth at $1,3,4$, and 5 years; the proportion of patients with local regrowth undergoing salvage surgery and, among those, the proportion who achieved R0 status (negative resection margin); 5-year overall survival (from date of first treatment); 5-year non-regrowth disease-free survival (from date of first treatment), as detailed in our previous work; ${ }^{2,18}$ and 3-year rate of distant metastasis (from date of first treatment). After registration of the protocol, we added an additional secondary outcome of 3-year survival post-salvage surgery (from date of salvage surgery).

\section{Statistical analysis}

We used Stata version 14.0 in our analyses. For tables of study characteristics, we summarised proportions and medians (with IQRs) and compared data with $\chi^{2}$ and Kruskal-Wallis tests across studies.

To derive summary estimates of local regrowth cumulative incidences, we took two approaches. In our main model, we used a two-stage individual participant data approach; we undertook time-to-event analyses per dataset to determine 2-year cumulative incidence of local regrowth with 95\% CIs using 1 minus Kaplan-Meier analyses, and then combined the outputs using a and Ludwig Institute for Cancer Research, Molecular Biology and Genomics Lab, São Paulo, Brazil (G Sao Julião MD, R O Perez) Correspondence to: Prof Andrew G Renehan, Division of Cancer Sciences, School of Medical Sciences, Faculty of Biology, Medicine and Health, University of Manchester, The Christie NHS Foundation Trust, Manchester M20 4BX, UK andrew.renehan@manchester. acuk 


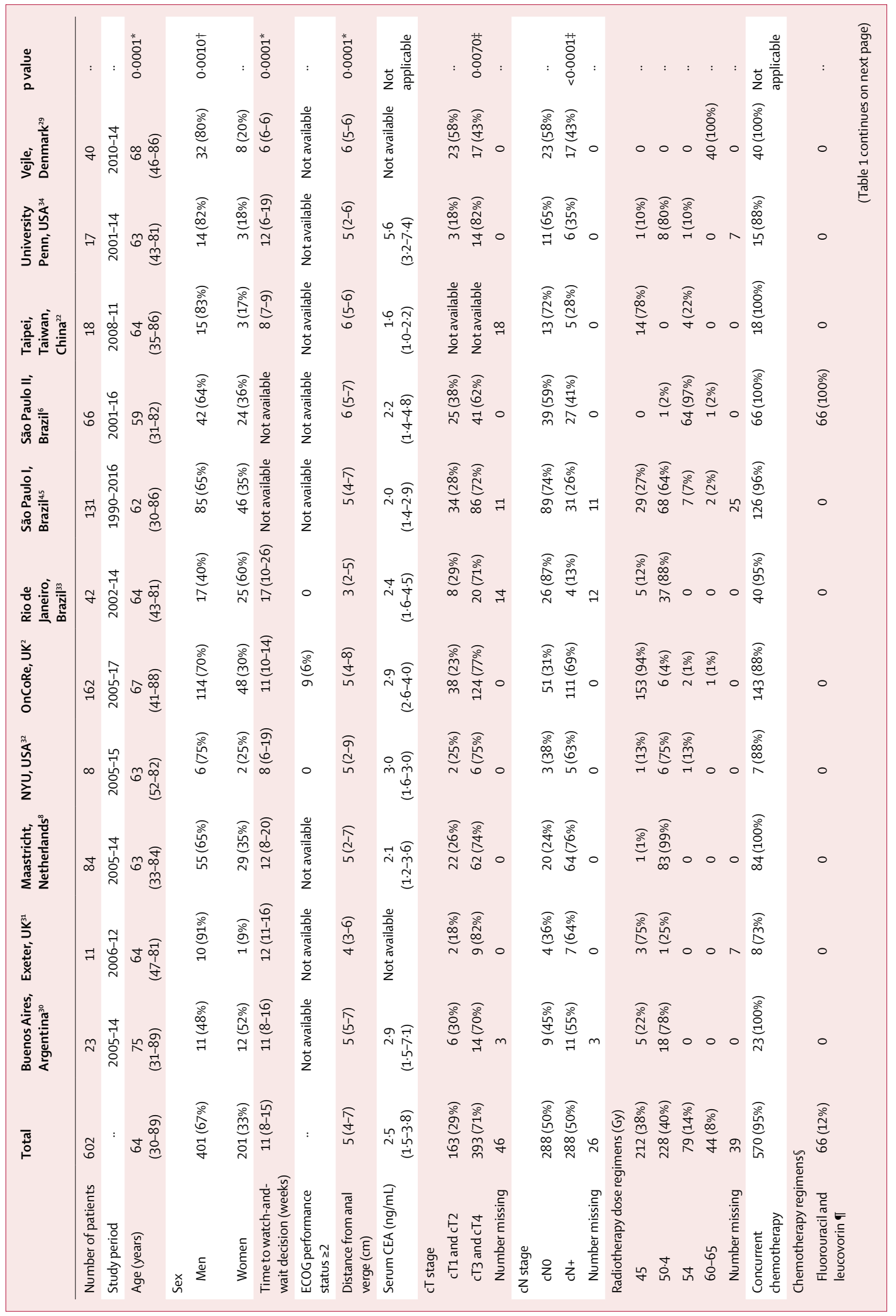


random-effects method with the admetan command. We assessed between-study heterogeneity with the $I^{2}$ statistic and assigned adjectives of low, moderate, and high to $I^{2}$ values close to $25 \%, 50 \%$, and $75 \%$, respectively. ${ }^{19} \mathrm{We}$ repeated this for local regrowth cumulative incidences at $1,3,4$, and 5 years. For yearly summary estimates, we additionally derived prediction intervals. Second, we pooled data from all datasets and reported cumulative incidence of local regrowth for each year from 1 year up to 5 years as 1 minus Kaplan-Meier and $95 \%$ CIs, without accounting for within-centre correlations. We refer to our main (preferred) analysis as random effects and our second analysis as pooled analysis.

We assessed the effect of clinical and treatment covariates on local regrowth. Initially, we reported univariable pooled analysis, and compared as required using log-rank tests. For multivariable modelling, we used Cox frailty models, with results expressed as hazard ratios (HRs) and 95\% CIs. These models introduce a randomeffects approach to account for associations and unobserved heterogeneity due to participation of different centres. $^{20}$ In the context of the present study, this approach accounts for unmeasured factors at each study level such as centre-level protocols for staging, treatment, and follow-up. Frailty models are increasingly reported in multicentre trial analyses to account for centre-level variations in clinical practice outside the trial protocol. ${ }^{21}$ A limitation of the Cox frailty model occurs if one attempts to evaluate a predictor where certain values of that covariate exist only in specific centres. This limitation is similar to the co-linearity problem in regression models. From Cox frailty models, we derived theta $(\theta)$ values and their standard errors and tested for $\theta=0$ using the likelihood ratio test to quantify betweencentre variability. If $\mathrm{p}$ values were less than $0 \cdot 01$, the correlation between participants within centres could not be ignored. To approximate the effect of measured factors on between-centre heterogeneity, we performed frailty models with and without covariates, and derived percentage mean differences in $\theta$ values. We tested assumptions of proportionality using Schoenfeld residuals and by visualising predicted versus observed survival plots.

There were 11 core variables: age, sex, performance status, baseline serum carcinoembryonic antigen (CEA), radiotherapy dose, initial treatment chemotherapy regimen, time to watch-and-wait decision, cT stage, $\mathrm{cN}$ stage, tumour distance from anal verge, and use of adjuvant chemotherapy. The proportion of missing data was generally low. Data were complete for age and sex, and missing for $4 \%$ of participants for $\mathrm{cN}$ stage; $8 \%$ for cT stage; and $7 \%$ for tumour distance from anal verge; these five covariates formed the basis for multivariable model A (ten datasets). Model B was model A plus time to decision for watch and wait, based on eight datasets (this variable was not calculable for the two São Paulo datasets $\left.^{4,6}\right)$. Model $\mathrm{C}$ was model A plus serum CEA 
concentration; values for CEA concentration were missing for $45 \%$ of participants. Radiotherapy dose was missing for $6 \%$ of participants, but was near totally coincident with centre status (the previously mentioned co-linearity problem), and was reported only in univariable models. In multivariable models, the continuous variables time to decision for watch and wait and serum CEA concentration were modelled using fractional polynomials. ${ }^{22}$

For reporting proportions among patients undergoing salvage surgery, we used a two-stage individual participant data approach, first estimating proportions (using the metaprop command) with 95\% CIs, and then combined using random-effects methods. For the outcomes of overall survival, non-regrowth disease-free survival, and distant metastases, we used similar twostage meta-analysis approaches to those used for cumulative incidence of local regrowth.

For interpretation of significance, we used the language recommended by Pocock and Ware ${ }^{23}$ (weak evidence for $0.05<\mathrm{p}<0.10$; some evidence for $0.01<\mathrm{p}<0.05$; and strong evidence for $\mathrm{p}<0 \cdot 001$ ).

\section{Post-protocol stratified analysis}

After full data collection, it became clear that enrolment dates ranged from March 11, 1990, to Feb 13, 2017, meaning that some of the data were older than anticipated in the initial protocol. We postulated that there was risk of misclassification in pretreatment staging across such a long period, and thus we performed a post-hoc stratified analysis restricted to patients enrolled after Jan 1, 2008. We judged this analysis to reflect contemporary clinical practice, whereby pretreatment staging is generally done by high-resolution MRI assessment using the MERCURY study ${ }^{24}$ principles.

\section{Publication bias, data availability bias, and reviewer selection bias}

We assessed for publication bias using contour-enhanced funnel plots and the asymmetry test in accordance with recommendations from Sterne and colleagues. ${ }^{25}$ As per principles set out by Ahmed and colleagues ${ }^{26}$ we assessed for data availability bias by deriving summary estimates from abstracts that were included in the meta-analysis by Dossa and colleagues ${ }^{9}$ and comparing with our summary estimates generated using individual participant data. Similarly, we assessed for reviewer selection bias (individual participant data sought from only a subset of known studies) by deriving summary estimates from published studies not included in this study (taken mainly from the meta-analysis by Dossa and colleagues ${ }^{9}$ ) and comparing with our summary estimates generated using individual participant data. The protocol for this meta-analysis was registered with PROSPERO (CRD42017070934).

\section{Role of the funding source}

There was no funding source for this study. SAC, LM, JE, RDR, and AGR had access to all data. SAC, RDR, GLB, $R P$, and AGR shared the responsibility for the final decision to submit for publication.

\section{Results}

A flow diagram of the study selection and reasons for exclusion of studies are provided in the appendix (pp 3-5). We initially received data from 12 studies, but excluded one study ${ }^{27}$ in which all patients received contact Papillon brachytherapy. The large São Paulo series was two distinct cohorts; patients in the early series (São Paulo $I^{4,5}$ ) received neoadjuvant chemoradiotherapy consisting of $50.4 \mathrm{~Gy}$ and two cycles of fluorouracil;

\begin{tabular}{|c|c|c|c|c|c|}
\hline & Patients & $\begin{array}{l}\text { Events at } \\
2 \text { years }\end{array}$ & & $\begin{array}{l}\text { Estimate, \% } \\
(95 \% \mathrm{Cl})\end{array}$ & $\begin{array}{l}\text { Weight } \\
\text { (\%) }\end{array}$ \\
\hline Exeter, UK ${ }^{31}$ & 11 & $\longrightarrow$ & $\longrightarrow$ & $36 \cdot 4 \%(15 \cdot 5-70 \cdot 3)$ & $3.9 \%$ \\
\hline OnCoRe, UK² & 162 & $\longrightarrow$ & & $35 \cdot 4 \%(28 \cdot 3-43 \cdot 7)$ & $13 \cdot 5 \%$ \\
\hline São Paulo II, Brazil ${ }^{6}$ & 66 & \begin{tabular}{ll}
1 \\
\hdashline
\end{tabular} & & $26 \cdot 9 \%(17 \cdot 6-39 \cdot 8)$ & $11 \cdot 0 \%$ \\
\hline São Paulo I, Brazil|4.5 & 131 & 32 & & $26 \cdot 3 \%(19 \cdot 3-35 \cdot 1)$ & $13 \cdot 3 \%$ \\
\hline Vejle, Denmark ${ }^{29}$ & 40 & 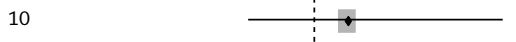 & & $25 \cdot 3 \%(14 \cdot 5-41 \cdot 9)$ & $9 \cdot 2 \%$ \\
\hline NYU, USA ${ }^{32}$ & 8 & 2 & $\rightarrow$ & $25 \cdot 0 \%(6 \cdot 9-68 \cdot 5)$ & $3 \cdot 2 \%$ \\
\hline Rio de Janerio, Brazil|33 & 23 & $\longrightarrow$ & & $17 \cdot 4 \%(6 \cdot 9-39 \cdot 9)$ & $7 \cdot 6 \%$ \\
\hline Buenos Aires, Argentina ${ }^{30}$ & 42 & $\longrightarrow$ & & $15 \cdot 3 \%(7 \cdot 2-31 \cdot 1)$ & $10 \cdot 4 \%$ \\
\hline Maastricht, Netherlands ${ }^{8}$ & 84 & $\longrightarrow$ & & $13 \cdot 3 \%(7 \cdot 6-22 \cdot 8)$ & $13 \cdot 6 \%$ \\
\hline Taipei, Taiwan, China $^{28}$ & 18 & $\longrightarrow$ & & $7 \cdot 3 \%(0 \cdot 9-36 \cdot 8)$ & $7 \cdot 0 \%$ \\
\hline \multirow{5}{*}{$\begin{array}{l}\text { University Penn, USA }{ }^{34} \\
\text { Overall }\left(I^{2}=61 \cdot 0 \%\right) \\
\text { Estimated prediction interval }\end{array}$} & 17 & $\longrightarrow$ & & $5 \cdot 9 \%(0 \cdot 9-35 \cdot 0)$ & $7 \cdot 4 \%$ \\
\hline & & & & $21 \cdot 4 \%(15 \cdot 3-27 \cdot 6)$ & $100 \cdot 0 \%$ \\
\hline & & & & $(2 \cdot 9-40 \cdot 0)$ & \\
\hline & & $20 \% \quad 40 \%$ & $60 \%$ & & \\
\hline & & Local regrowth (95\% Cl) & & & \\
\hline
\end{tabular}

Figure 1: Forest plot of 11 datasets

Centres are sorted by descending 2-year cumulative incidence of local regrowth. Summary estimate, 95\% Cls, and prediction intervals shown for random-effects method. $\mathrm{NYU}=$ New York University. University Penn=University of Pennsylvania. 
whereas patients in the later series (São Paulo $\mathrm{II}^{6}$ ) were treated with an extended regimen of $54 \mathrm{~Gy}$ and six cycles of fluorouracil.

Our final analysis included 11 studies. ${ }^{2,46,6,828-34}$ The definitions for clinical complete response across all datasets were judged to be equivalent to São Paulo benchmarks ${ }^{5,16}$ (appendix pp 6-7). 602 patients enrolled between March 11, 1990 and Feb 13, 2017, were included in the analysis, of whom 108 were not reported in the previously published papers (appendix p 8). We noted two clinical indications among the studies: standard practice neoadjuvant chemoradiotherapy in which clinical complete response rates ranged from $12 \%$ to $49 \%$, and high-dose or extended neoadjuvant chemoradiotherapy with intended enhanced clinical complete response rates ranging from $68 \%{ }^{4}$ to $73 \% .{ }^{29}$

Patient, tumour, and treatment characteristics, by dataset, are summarised in table 1 . We noted wide variation in clinical and tumour characteristics. Median age ranged from 59 to 75 years $(\mathrm{p}=0 \cdot 0001)$; the proportion of men ranged from $40 \%$ to $91 \%(\mathrm{p}=0.0010)$; median distance of tumour from anal verge ranged from $3 \mathrm{~cm}$ to $6 \mathrm{~cm}$ ( $\mathrm{p}=0.0001)$; the proportion of patients with cT3 or cT4 tumours ranged from $43 \%$ to $82 \%(\mathrm{p}=0 \cdot 0070)$; the proportion of patients with nodal positive $(\mathrm{cN}+)$ disease ranged from $13 \%$ to $76 \%(\mathrm{p}<0 \cdot 0001)$; and median time to watch-and-wait decision ranged from 6 weeks to 17 weeks $(\mathrm{p}=0 \cdot 0001)$. Radiotherapy treatment protocols also differed between studies, and concurrent chemotherapy (fluorouracil-based in 518 [91\%] of 570) was used in all series, and in at least $95 \%$ of patients in seven datasets. Using the modified IHEQA checklist, ${ }^{17}$ we judged ten of the 11 datasets to be at low risk of bias, and one ${ }^{8}$ to be at moderate risk (appendix p 9).

Overall, median follow-up was 37.6 months (IQR 25.0-58.7), ranging from 12.4 months to 60 months between studies. Local regrowth occurred in 166 patients (crude proportion 28\%). The summary 2-year cumulative incidence of local regrowth was $21.4 \%$ (random-effects 95\% CI 15·3-27.6), with a high level of between-study heterogeneity ( $I^{2}=61 \%$; figure 1$)$.

Incidences of local regrowth from 1 year up to 5 years for the pooled analysis and the two-stage random-effects meta-analysis are shown in figure 2. Compared with the pooled analysis, summary point estimates for the twostage random-effects meta-analysis were more conservative but with wider 95\% CIs. Local regrowth occurred almost exclusively in the first 3 years (155 [93\%] of 166). We assessed visually for proportionality of local regrowth curves with time across the 11 datasets and found similar patterns in all datasets (appendix p 10).

We tested for factors predicting local regrowth, initially for the total set of cohorts, and then for a subgroup of 459 patients managed after 2008 (table 2). For the total set of cohorts, we found some evidence that incre asing cT stage was associated with increased risk of local regrowth. By univariable analysis, 2-year cumulative

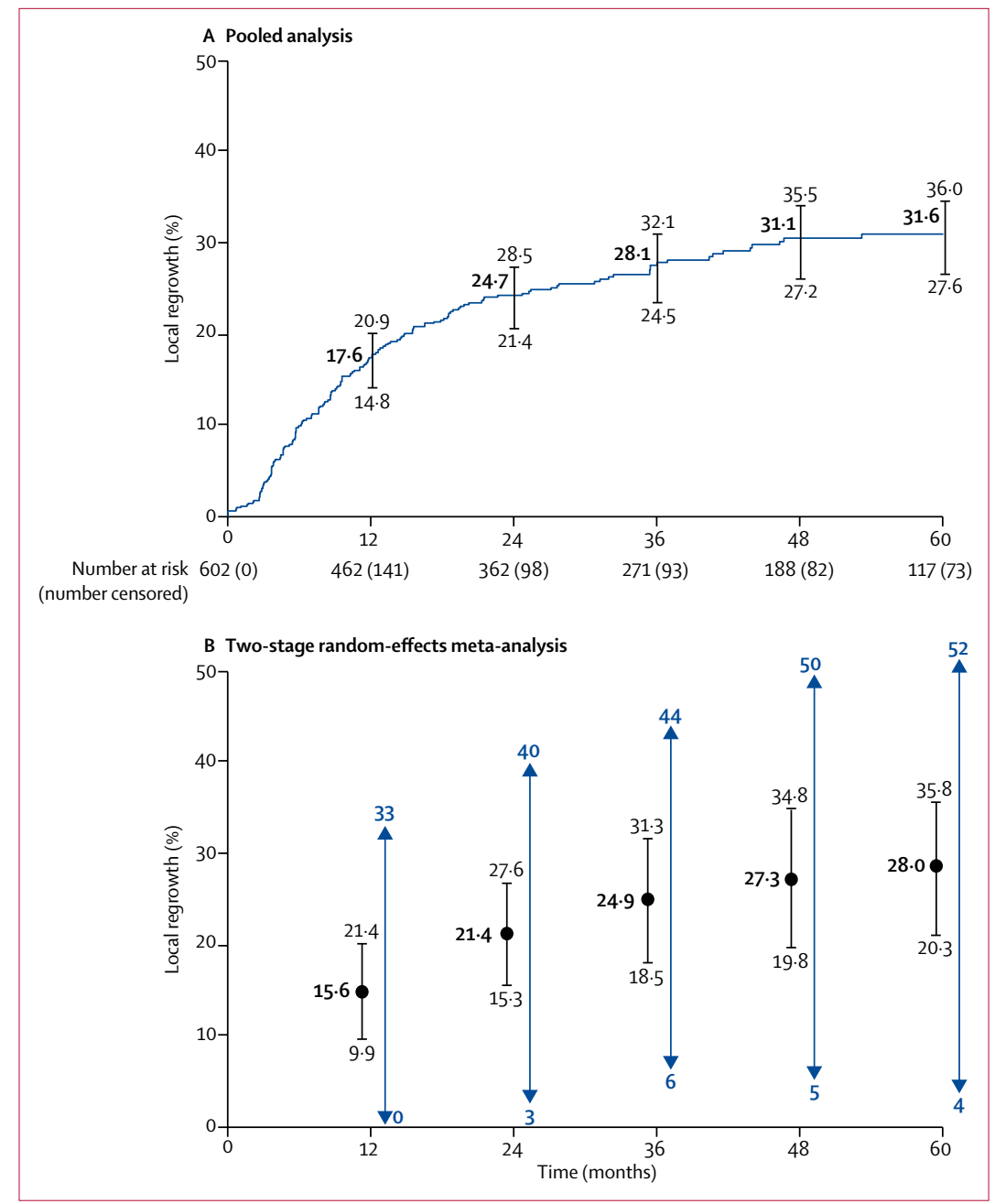

Figure 2: Incidence of local regrowth

(A) Pooled analysis of cumulative incidence of local regrowth from 1 year to 5 years, with $95 \% \mathrm{Cls}$. (B) Two-stage random-effect meta-analysis with summary estimates for 1 year up to 5 years, with $95 \%$ Cls. Predictive intervals are shown in blue.

incidences were $18 \%$ (95\% CI 13-25) for stages cT1 and cT2, $29 \%$ (24-34) for cT3, and 31\% (17-52) for cT4. In the multivariable frailty model A, including age, sex, cT stage, $\mathrm{cN}$ stage, and tumour distance from anal verge, the HR per cT stage increase was 1.40 (random-effects 95\% CI 1.00-1.94; $\left.\mathrm{p}_{\text {trend }}=0 \cdot 0480\right)$. No associations were noted among other factors included in model A or in the other models.

For the subgroup of patients managed after 2008, 2-year cumulative incidence of local regrowth increased in a stepwise manner from $19 \%$ (95\% CI 13-28) for stage cT1 and cT2 tumours, 31\% (26-37) for cT3, to 37\% (21-60) for cT4. In model A, the HR per cT stage increase was $1 \cdot 50$ (random-effects 95\% CI 1.03-2.17; $\mathrm{p}_{\text {trend }}=0 \cdot 0330$ ).

We tested (likelihood ratio test) for $\theta=0$ and found significance in all models, indicating that correlation within centres could not be ignored (table 3 ). We compared $\theta$ values in each model (A to C) with and without 
added factors, and noted that the likelihood ratio test remained significant and addition of the measured factors only modestly affected $\theta$. Measured factors contributed an estimated $4.8 \%$ to $45 \cdot 3 \%$ to betweenstudy heterogeneity.

Of the 166 patients with local regrowth, 137 had salvage surgery (random-effects estimate 89\% [95\% CI 80-98]; table 4). R0 status was achieved in 131 of these patients (random-effects 98\% [95-100]). After histopathological examination, only four patients were pT4; most (59 patients) were pT3 (random-effects 44\% [30-58]).
Node positivity was noted in 18 resections (randomeffects $16 \%$ [5-27]).

The 137 patients with local regrowth who underwent salvage surgery were younger than the 29 patients treated by non-surgical strategies (median age 65.2 years [IQR 57.4-71.2] vs 70.3 years [60.9-76.0], respectively; $\mathrm{p}=0.0374)$. The most common reason for no salvage surgery was synchronous distant metastases (12 patients) or being unfit, mainly associated with older age (ten patients aged $\geq 75$ years). 3-year post-salvage survival was $80 \cdot 1 \%(95 \%$ CI $70 \cdot 3-87 \cdot 0)$; 3-year survival in

\begin{tabular}{|c|c|c|c|c|c|c|c|c|}
\hline & \multicolumn{4}{|c|}{ Total cohort $(n=602)$} & \multicolumn{4}{|c|}{ Post-2008 subcohort $(n=459)$} \\
\hline & $\begin{array}{l}\text { Number of } \\
\text { patients }\end{array}$ & $\begin{array}{l}\text { Pooled analysis 2-year } \\
\text { cumulative incidence of } \\
\text { local growth, } \%(95 \% \mathrm{Cl})\end{array}$ & $\begin{array}{l}\text { Frailty model } \\
\text { univariable } \mathrm{HR} \\
\text { (random-effects } \\
95 \% \mathrm{Cl} \text { ) }\end{array}$ & $\begin{array}{l}\text { Frailty model } \\
\text { multivariable* } \mathrm{HR} \\
\text { (random-effects } \\
95 \% \mathrm{Cl} \text { ) }\end{array}$ & $\begin{array}{l}\text { Number of } \\
\text { patients }\end{array}$ & $\begin{array}{l}\text { Pooled analysis 2-year } \\
\text { cumulative incidence of } \\
\text { local growth, } \%(95 \% \mathrm{Cl})\end{array}$ & $\begin{array}{l}\text { Frailty model } \\
\text { univariable } \mathrm{HR} \\
\text { (random-effects } \\
95 \% \mathrm{Cl} \text { ) }\end{array}$ & $\begin{array}{l}\text { Frailty model } \\
\text { multivariable* } \mathrm{HR} \\
\text { (random-effects } \\
95 \% \mathrm{Cl} \text { ) }\end{array}$ \\
\hline All patients & 602 & $25 \%(21-28)$ & .. & .. & 459 & $27 \%(23-31)$ & .. & .. \\
\hline \multicolumn{9}{|l|}{ Age group } \\
\hline Per 10 years & 602 &.. & $1.01(0.88-1 \cdot 16)$ & $0.95(0.82-1.11)$ & 459 &.$\cdot$ & $0.92(0.79-1.09)$ & $0.90(0.76-1.07)$ \\
\hline \multicolumn{9}{|l|}{ Sex } \\
\hline Women & 201 & $23 \%(18-30)$ & 1 (ref) & 1 (ref) & 155 & $22 \%(16-30)$ & 1 (ref) & 1 (ref) \\
\hline Men & 401 & $25 \%(21-30)$ & $1.17(0.84-1.63)$ & $1.19(0.93-1.06)$ & 304 & $29 \%(24-31)$ & $1.44(0.97-2 \cdot 13)$ & $1.53(1.02-2 \cdot 30)$ \\
\hline \multicolumn{9}{|l|}{ cT stage } \\
\hline $\mathrm{cT} 1$ and $\mathrm{cT} 2$ & 163 & $18 \%(13-25)$ & 1 (ref) & 1 (ref) & 125 & $19 \%(13-28)$ & 1 (ref) & 1 (ref) \\
\hline cT3 & 367 & $29 \%(24-34)$ & $1.40(0.96-2.03)$ & $1.43(0.95-2.14)$ & 282 & $31 \%(26-37)$ & $1 \cdot 55(1.01-2 \cdot 39)$ & $1 \cdot 66(1.07-2 \cdot 58)$ \\
\hline cT4 & 26 & $31 \%(17-52)$ & $1.53(0.73-3 \cdot 19)$ & $1.86(0.84-4.13)$ & 22 & $37 \%(21-60)$ & $1.71(0.77-3 \cdot 80)$ & $1.90(0.85-4.27)$ \\
\hline Per cT stage increase &.$\cdot$ &.. & $1 \cdot 348(1.00-1 \cdot 82)$ & $1.40(1.00-1.94)$ & .. &.$\cdot$ & $1.45(1.04-2.04)$ & $1 \cdot 50(1.03-2 \cdot 17)$ \\
\hline \multicolumn{9}{|l|}{ cN stage } \\
\hline $\mathrm{cNO}$ & 288 & $25 \%(21-31)$ & 1 (ref) & 1 (ref) & 192 & $28 \%(22-35)$ & 1 (ref) & 1 (ref) \\
\hline $\mathrm{cN}+$ & 288 & $24 \%(19-30)$ & $0.91(0.65-1.27)$ & $0.87(0.61-1.24)$ & 256 & $26 \%(21-32)$ & $0.91(0.63-1.31)$ & $0.75(0.51-1 \cdot 10)$ \\
\hline \multicolumn{9}{|c|}{ Distance from anal verge $(\mathrm{cm}) \dagger$} \\
\hline$<6 \cdot 0$ & 311 & $25 \%(20-30)$ & 1 (ref) & 1 (ref) & 264 & $27 \%(22-33)$ & 1 (ref) & 1 (ref) \\
\hline$\geq 6 \cdot 0$ & 246 & $23 \%(18-29)$ & $0.94(0.67-1.32)$ & $0.90(0.63-1.27)$ & 160 & $23 \%(17-31)$ & $0.81(0.55-1.20)$ & $0.77(0.51-1.15)$ \\
\hline \multicolumn{9}{|l|}{ Serum CEA $(\mathrm{ng} / \mathrm{mL}) \dagger$} \\
\hline$<3 \cdot 0$ & 219 & $29 \%(23-35)$ & 1 (ref) & Not included $\neq$ & 164 & $32 \%(25-40)$ & 1 (ref) & Not included $\ddagger$ \\
\hline $3 \cdot 0-9 \cdot 9$ & 88 & $19 \%(12-29)$ & $0.70(0.42-1.18)$ & Not included $\neq$ & 71 & $20 \%(13-32)$ & $0 \cdot 70(0 \cdot 40-1 \cdot 24)$ & Not included $\neq$ \\
\hline$\geq 10$ & 22 & $36 \%(20-55)$ & $1.54(0.79-3.02)$ & Not included $\neq$ & 18 & $39 \%(30-65)$ & $1 \cdot 54(0 \cdot 75-3 \cdot 16)$ & Not included $\ddagger$ \\
\hline \multicolumn{9}{|l|}{ Radiotherapy dose (Gy) } \\
\hline 45 & 212 & $30 \%(24-37)$ & 1 (ref) & Not appropriate $\S$ & 187 & $33 \%(26-40)$ & 1 (ref) & Not appropriate $\$$ \\
\hline $50 \cdot 4$ & 228 & $19 \%(14-25)$ & $0.90(0.56-1.44)$ & Not appropriate $\$$ & 161 & $19 \%(13-26)$ & $0.57(0.33-0.99)$ & Not appropriate \\
\hline 54 & 79 & $30 \%(21-42)$ & $1.54(0.75-3 \cdot 14)$ & Not appropriate $\$$ & 38 & $40 \%(26-60)$ & $1.49(0.74-3.01)$ & Not appropriate $\$$ \\
\hline $60-65$ & 44 & $26 \%(15-41)$ & $1.00(0.41-2 \cdot 40)$ & Not appropriate $\$$ & 43 & $26 \%(15-42)$ & $0 \cdot 81(0 \cdot 36-1 \cdot 82)$ & Not appropriate $\$$ \\
\hline \multicolumn{9}{|c|}{ Intention to enhance clinical complete response } \\
\hline Yes (two studies) & 106 & $26 \%(19-36)$ & 1 (ref) & Not appropriate $\$$ & 67 & $28 \%(19-41)$ & 1 (ref) & Not appropriate $§$ \\
\hline No (nine studies) & 496 & $24 \%(21-29)$ & $1.13(0.57-2 \cdot 21)$ & Not appropriate $\$$ & 392 & $26 \%(22-31)$ & $1.11(0.53-2 \cdot 30)$ & Not appropriate $\$$ \\
\hline \multicolumn{9}{|c|}{ Time to watch-and-wait decision (weeks) $\mathbb{\top}$} \\
\hline$<13$ & 264 & $23 \%(18-29)$ & 1 (ref) & Not included $\ddagger$ & 239 & $25 \%(20-33)$ & 1 (ref) & Not included $\ddagger$ \\
\hline$\geq 13$ & 141 & $25 \%(19-34)$ & $1 \cdot 21(0.81-1 \cdot 82)$ & Not included $\ddagger$ & 134 & $27 \%(20-36)$ & $1.15(0 \cdot 77-1 \cdot 73)$ & Not included $\ddagger$ \\
\hline \multicolumn{9}{|c|}{$\begin{array}{l}\text { Frailty models account for centre effect. Analyses in post- } 2008 \text { subcohort limited to model of age, sex, } \mathrm{cT} \text { stage, } \mathrm{cN} \text { stage, and tumour distance from anal verge (equivalent to model A in table } 3 \text { ). } \mathrm{cT} \text { and } \mathrm{cN} \\
\text { staging according to American Joint Committee on Cancer } 7 \text { th edition. CEA=carcinoembryonic antigen. HR=hazard ratio. *For the full cohort, the complete case multivariable model was based on } 514 \text { patients, } \\
\text { equivalent to model A in table } 3 \text {. For the post- } 2008 \text { cohort, the complete case multivariable model was based on } 393 \text { patients. †Categorisation cutoff points for tumour distance from anal verge and serum CEA } \\
\text { concentration were based on clinical reasons. Tumour distance from anal verge of } 6 \mathrm{~cm} \text { was taken as equivalent to that commonly used to define low-rectal cancers. } \neq \text { Not included in multivariable model because } \\
\text { of substantial proportion of missing data. SNot appropriate because of coincidence of radiotherapy dose and study centre. } \uparrow \text { Cutoff point of } 13 \text { weeks determined using spline approaches; equivalent to model B } \\
\text { in table 3. }\end{array}$} \\
\hline
\end{tabular}


patients not undergoing salvage surgery was $55.3 \%$ (30.0-74.8; appendix p 11). Accounting for age at local regrowth and between-centre variation, this difference was not significant $(\mathrm{p}=0 \cdot 2140)$.

68 deaths occurred. 5-year overall survival was $87.0 \%$ (random-effects 95\% CI 81.5-92.4), and 5-year non-regrowth disease-free survival was $81.3 \%$ (randomeffects 95\% CI 74.9-87.6; appendix p 12). Distant metastases were reported in 60 patients (appendix p 13). 3 -year incidence of distant metastasis was $9 \cdot 1 \%$ (randomeffects $95 \%$ CI 8.7-9.5). The most common sites of distant metastases were lung (31 [52\%] of 60 patients) and liver (23 [38\%] of 60 patients; appendix p 13). $31(52 \%)$ of 60 patients with distant metastases had local regrowth. Distant metastasis was identified synchronous with local regrowth in 12 patients, after local regrowth in 14 patients, and before local regrowth in only four patients (dates were missing for one patient; appendix $\mathrm{p}$ 13).

We visually inspected the funnel plot for the 11 included datasets for asymmetry and found no evidence indicating publication bias (appendix p 14). For the primary outcome of 2-year cumulative incidence of local regrowth, we found no evidence for data availability bias (random-effects $21.4 \%$ [95\% CI 15·1-27.7] for estimates in the individual participant data meta-analysis vs $13.9 \%$ [7.9-19.8] for estimates from data available in abstractform only; $\mathrm{p}_{\text {interaction }}=0 \cdot 1110$; appendix $\mathrm{p} 15$ ) and weak evidence for reviewer selection bias (random-effects $21.4 \%$ [95\% CI 15 - 1-27.7] for estimates in the individual participant data meta-analysis vs $11 \cdot 5 \%$ [5-3-17.7] for estimates of other known published studies not included in the present analysis; $p_{\text {interaction }}=0 \cdot 0890$; appendix $\mathrm{p} 16$ ).

\section{Discussion}

We report five main findings. First, among studies of patients with rectal cancer and clinical complete response after chemoradiotherapy managed by watch and wait, there was wide variation in baseline patient, tumour, and treatment characteristics, but overall, study quality was at low risk of bias. Second, 2-year cumulative incidence of local regrowth was approximately $20 \%$, but there was wide variation across studies. Third, we found some evidence that increasing $\mathrm{cT}$ stage was associated with increased risk of local regrowth, particularly in a subgroup of patients managed after 2008, but we found no clear signal of associations between other factors and risk of local regrowth. Fourth, the observed betweenstudy heterogeneity might partly be explained by study differences in measured factors, such as cT stage, but other unmeasured predictors might be relevant and should be investigated in future research. Finally, we described several secondary outcomes, which will inform clinician-patient decision making. These include the findings that salvage surgery rates were high after tumour local regrowth, with almost all patients achieving R0 status and favourable 3-year post-salvage survival.
Overall incidence of distant metastasis was low; and overall survival rates were favourable.

Two published study-level meta-analyses ${ }^{9,10}$ and one large registry-based review ${ }^{11}$ have estimated local regrowth

\begin{tabular}{|c|c|c|c|c|c|}
\hline & Covariates in model & Mean $\theta(\mathrm{SE})$ & $\begin{array}{l}\text { Difference } \\
\text { in } \theta(\%)\end{array}$ & $\begin{array}{l}\text { Likelihood } \\
\text { of } \theta=0\end{array}$ & AIC \\
\hline \multicolumn{6}{|l|}{ Total cohort } \\
\hline \multicolumn{6}{|c|}{ Model A (514 patients)* } \\
\hline No covariates & None & $0 \cdot 12(0 \cdot 10)$ &.. & 0.002 & $1673 \cdot 7$ \\
\hline With covariates & $\begin{array}{l}\text { Age, sex, cT stage, cN stage, } \\
\text { distance from anal verge }\end{array}$ & $0.12(0 \cdot 10)$ & $4.8 \%$ & 0.003 & $1680 \cdot 2$ \\
\hline \multicolumn{6}{|c|}{ Model B (337 patients) } \\
\hline No covariates & None & $0.18(0.15)$ &.. & 0.001 & $981 \cdot 5$ \\
\hline With covariates & $\begin{array}{l}\text { Age, sex, cT stage, cN stage, } \\
\text { distance from anal verge, time } \\
\text { to watch-and-wait decision }\end{array}$ & $0.26(0.21)$ & $45 \cdot 3 \%$ & 0.001 & $978 \cdot 3$ \\
\hline \multicolumn{6}{|c|}{ Model C (278 patients) } \\
\hline No covariates & None & $0.27(0 \cdot 21)$ &.. & $<0.001$ & $872 \cdot 2$ \\
\hline With covariates & $\begin{array}{l}\text { Age, sex, cT stage, cN stage, } \\
\text { distance from anal verge, } \\
\text { baseline serum CEA }\end{array}$ & $0.25(0.19)$ & $7 \cdot 4 \%$ & 0.001 & $870 \cdot 9$ \\
\hline \multicolumn{6}{|c|}{ Post-2008 subcohort } \\
\hline \multicolumn{6}{|c|}{ Model A (393 patients) } \\
\hline No covariates & None & $0.10(0.08)$ &.. & 0.005 & $1234 \cdot 4$ \\
\hline With covariates & $\begin{array}{l}\text { Age, sex, cT stage, cN stage, } \\
\text { distance from anal verge }\end{array}$ & $0.11(0.09)$ & $12 \cdot 4 \%$ & 0.003 & 1233.9 \\
\hline
\end{tabular}

Tumour distance from anal verge, time to watch-and-wait decision, and serum CEA concentration as continuous variables. Time to watch-and-wait decision as a spline pivoted as 13 weeks (determined from fractional polynomials) $\mathrm{AIC}=$ Akaike Information Criteria. $\mathrm{CEA}=$ carcinoembyronic antigen. ${ }^{*}$ Patients included here might have had missing data for some variables but not others.

Table 3: Outputs from frailty models clustering for centres and assessing changes in between-study heterogeneity $(\theta)$ for local regrowth, with and without covariates

\begin{tabular}{|c|c|c|c|c|c|}
\hline & \multirow[t]{2}{*}{ Number (\%) } & \multicolumn{4}{|c|}{ Post-salvage surgery pathology findings } \\
\hline & & $\begin{array}{l}\text { Positive } \\
\text { CRM }\end{array}$ & $\begin{array}{l}\text { Positive } \\
\text { DRM }\end{array}$ & $\begin{array}{l}\text { ypT stage* (To/T1/ } \\
\text { T2/T3/T4/missing) }\end{array}$ & $\begin{array}{l}\text { ypN stage* } \\
\text { (No/N+/missing) }\end{array}$ \\
\hline $\begin{array}{l}\text { Number of patients with } \\
\text { local regrowth }\end{array}$ & 166 & .. &.. &.. &.. \\
\hline Non-surgical treatments & $29+(17 \%)$ & .. &.. & .. & .. \\
\hline Surgical treatments & $137(83 \%)$ & .. &.. &.. & .. \\
\hline \multicolumn{6}{|l|}{ Operation types } \\
\hline $\begin{array}{l}\text { Abdominoperineal } \\
\text { resection }\end{array}$ & $73(53 \%)$ & 4 & 0 & $1 / 7 / 22 / 35 / 2 / 6$ & $56 / 9 / 8$ \\
\hline Anterior resection & $29(21 \%)$ & 0 & 0 & $3 / 5 / 6 / 14 / 0 / 1$ & $20 / 8 / 1$ \\
\hline Hartmann's procedure & $4(3 \%)$ & 0 & 1 & $0 / 0 / 0 / 3 / 0 / 1$ & $2 / 1 / 1$ \\
\hline Other radical operations & $6(4 \%)$ & 0 & 0 & $0 / 0 / 2 / 2 / 2 / 0$ & $6 / 0 / 0$ \\
\hline $\begin{array}{l}\text { Transanal local excision } \\
\text { or TEM }\end{array}$ & $25(18 \%)$ & $\begin{array}{l}\text { Not } \\
\text { applicable }\end{array}$ & 1 & 0/5/13/5/0/0 & Not applicable \\
\hline Total &.. & 4 & 2 & 4/17/43/59/4/8 & $84 / 18 / 10$ \\
\hline Total colostomies & $80(48 \%)$ &.. &.. &.$\cdot$ & .. \\
\hline \multicolumn{6}{|c|}{$\begin{array}{l}\text { Data are number of patients. Values in parentheses are percentages. CRM=circumferential resection margin. } \\
\text { DRM=distal resection margin. TEM=transrectal endoscopic microdissection. ypT=pathological } \mathrm{T} \text {-stage. } \\
\text { ypN=pathological } \mathrm{N} \text {-stage. *The Taiwan study did not contribute to the pathological } \mathrm{T} \text { and } \mathrm{N} \text { staging. } \\
\text { had synche patients } \\
\text { had stonous diagnoses of distant metastases. }\end{array}$} \\
\hline
\end{tabular}


rates, and one meta-analysis ${ }^{35}$ focused on salvage in patients with local regrowth. As in our study, Dossa and colleagues $^{9}$ found wide variation in baseline patient characteristics and 2-year local regrowth rates across studies. By contrast with the study by Dossa and colleagues, our analysis directly reported these baseline differences - for instance, median ages varied across the studies by as much as 16 years and the proportion of cT3 and cT4 tumours varied from $43 \%{ }^{29}$ to $82 \% .^{31}$ Dossa and colleagues reported a lower summary 2-year local regrowth $(15 \cdot 7 \%)$ than we report $(21.4 \%)$; our assessment of data availability bias suggests that this difference was mainly driven by the inclusion of eight unpublished abstracts in the Dossa review, ${ }^{9}$ but this difference was not statistically significant.

Dattani and colleagues ${ }^{10}$ reported a 3-year cumulative risk of local regrowth of $21.6 \%$, using a range of methods to estimate numbers at risk at 3 years to account for censoring, given the absence of individual time-to-event data. Thus, their estimate is broadly equivalent to our 2-year cumulative incidence of local regrowth of $21.4 \%$.

In the recent IWWD analysis of 880 participants, there were data on 552 participants from five centres (AJGI; OnCoRe; Maastricht; Hospital Italiano, Buenos Aires; Vejle) that also contributed to our analysis. While the inclusion criteria into our analysis were more stringent, given the overlap, not unexpectedly, similar estimates were seen for several, but not all, outcomes. Two-year cumulative incidence of local regrowth was $25 \cdot 2 \%$ (95\% CI $22 \cdot 2-28 \cdot 5)$ in IWWD versus $21.4 \%$ (randomeffects $95 \%$ CI $15 \cdot 3-27 \cdot 6$ ) in our analysis; 5-year overall survival was $84.7 \%$ (95\% CI $80 \cdot 9-87.7)$ versus $87.0 \%$ (random-effects 95\% CI 81.5-92.4); and 3-year incidence of distant metastasis was $8 \cdot 1 \%(95 \%$ CI $6 \cdot 2-10 \cdot 5)$ versus $9 \cdot 1 \%$ (random-effects 95\% CI 8.7-9.5). However, the proportion of patients who had salvage surgery was estimated to be $69 \%$ in the IWWD study compared with $89 \%$ in our study. R0 status was attained in $88 \%$ of patients in IWWD, whereas in almost all salvage operations in our analysis. We also report 3-year postsalvage overall survival $(80 \cdot 1 \%)$ and 5 -year non-regrowth disease-free survival $(81.3 \%)$, having previously argued that the latter is an informative outcome of disease control. $^{18}$

Although there were individual-level data in IWWD, ${ }^{11}$ data were pooled without taking account of betweenstudy differences. With high proportions of missing data for key confounders such as cT stage (18\%), the IWWD analysis was unable to assess predictive factors of tumour local regrowth. From our analyses, we observed some evidence that increasing cT stage was associated with increased risk of local regrowth, a finding that was also noted at a smaller scale in the São Paulo series. ${ }^{36}$

A systematic review by Kong and colleagues ${ }^{35}$ focused on the frequency of salvage surgery reported in studies in which patients were managed by watch and wait. The analysis included 370 patients from nine studies, of whom 256 (69\%) had sustained clinical complete response. The proportion of patients undergoing salvage surgery $(84 \%)$ was similar to our analysis $(89 \%)$.

Our study has limitations. First, we did not collect data on surveillance protocols. The IWWD study ${ }^{11}$ reported wide variation in frequency and assessment methods, and in theory, this might contribute to the observed between-study heterogeneity in key outcomes. We broadly controlled for this using frailty models, which account for centre-level heterogeneity, such as follow-up protocols. Second, the individual participant data metaanalysis approach does not resolve the potential problem of susceptibility to bias in included studies. We formally assessed for this bias and found that most studies were at low risk. Third, we sought data from only a subset of published studies, but we found only weak evidence of reviewer selection bias. Finally, we only approached investigators of published studies, which could result in data availability bias, although we found no strong evidence for this.

At first glance, a study weakness might be the absence of a comparator group. There is debate about the most appropriate comparator, such as patients with rectal cancer undergoing resection surgery and found to have a pathological complete response, or patients with a clinical complete response and treated by surgery. ${ }^{9}$ The choice of comparator group depends on the question; ${ }^{2}$ if the focus is oncological safety (eg, survival outcomes), the comparison group should be matched for key prognostic factors such as age, performance status, and tumour stage to minimise selection bias. By contrast, our aim here was to assess predictive factors for local regrowth, since these will inform clinical protocols.

Indeed, our assessment of predictors of local regrowth is a notable strength of our study. Moreover, we restricted studies to those that defined clinical complete response using criteria equivalent to São Paulo benchmarks in order to minimise baseline misclassification of clinical complete response and facilitate interpretation of our predictions. The use of individual participant data metaanalysis also allowed us to update and extend study-level information (eg, data for a sixth of participants were previously unreported); to identify published studies that contained overlapping sets of participants; to incorporate results from under-reported outcomes (eg, non-regrowth disease-free survival ${ }^{18}$ ); to verify results presented in the original study publications; to standardise the strategy for statistical analysis; and to assess model assumptions in each study. Specifically, we ran identical time-to-event analyses for each study, thus bypassing numbers at risk assumptions used in other meta-analyses. We purposefully strengthened our analytical design by seeking homogeneity of treatment; for example, some series $^{8,16}$ historically included local excisions as part of the initial watch-and-wait management from an era when it was thought that this additional step was necessary. Similarly, we excluded patients with a near complete 
clinical response, ${ }^{37}$ some of whom were treated by contact Papillion brachytherapy. ${ }^{38}$

Regarding the clinical relevance of this study, we have not identified a patient subgroup that is unsuitable for watch and wait. Although in the post-2008 post-hoc analysis, cT4 tumours were associated with 2-year cumulative incidence of local regrowth of about $40 \%$, more than half of patients potentially benefited from a sustained complete response. Going forward, there is a need to validate the associations between $\mathrm{CT}$ stage and local regrowth on the basis of standardised MRI-based pretreatment staging protocols.

Another clinical question is whether there should be a stratified approach to follow-up. Conceivably, one might argue that CT3 and cT4 tumours are at high risk of local regrowth, but given the high proportions of patients undergoing salvage surgery and attaining R0 status, it is questionable whether more intensive surveillance in this patient subgroup would substantially affect long-term outcomes. Similarly, the rate of distant metastases in all these patients is low, arguing that more regular CT surveillance is unlikely to have a major clinical impact.

What are the implications for future trials? Several trials are ongoing or in development in which rectal organ preservation is the primary aim. Our study included one such trial, ${ }^{29}$ and the selection of patients in the São Paulo II cohort ${ }^{6}$ fulfilled the same aim. We showed that these subpopulations had similar incidences of local regrowth to those who achieved clinical complete response through routine care.

There are several key areas for future research. First, there is a need to establish an internationally accepted definition of clinical complete response, and to establish the role of MRI in this definition. Research is also needed to determine other predictors of sustained clinical complete response. Several approaches exist including imaging, blood biomarkers, and tumour molecular phenotyping. There is also a need to engage with patients to assess their options and preferences. Evidence suggests that watch and wait is associated with substantially better quality of life and functional outcomes compared with standard surgical resection. ${ }^{39}$ But a major caveat is that chemoradiotherapy itself might be associated with long-term morbidity. To date, no study has included MRI-tailored approaches by surgery alone as a comparator. All three pathways (chemoradiotherapy plus resection $v$ s chemoradiotherapy plus watch and wait vs tailored resection alone) need to be investigated. Only then can we truly appraise the role of watch and wait in the overall standard care management of locally advanced rectal cancer.

\section{Contributors}

SAC, ROP, and AGR conceptualised the study. SAC performed literature searches and data extraction and harmonisation, with assistance from LM. SAC, RP, AGR, JE, RDR, AH-G, and SDW contributed to the design of the study, data analysis and interpretation, and writing of the report. JE, AGR, and RDR did the statistical analysis. All authors contributed to the final manuscript draft.

\section{Declaration of interests}

AGR reports personal fees from Merck Serono and Janssen-Cilag, and grants from Sanofi Pasteur MSD and Novo Nordisk, outside the submitted work. MPS reports personal fees from Merck, Amgen, Servier, Eisai, and Roche, outside the submitted work. IRD reports personal fees and other from Medtronic UK, Gore UK, and Bard; and personal fees, non-financial support, and other from Molnlycke, outside the submitted work. NJS reports personal fees from Medtronic and W L Gore, outside the submitted work. SDW reports personal fees from Intuitive Surgical, Karl Storz Endoscopy America, LifeBond, Medtronic, TiGenix, and Regentys, outside the submitted work; and patent/ intellectual property with Covidien, Intuitive Surgical, and Karl Storz Endoscopy America. All other authors declare no competing interests.

\section{Data sharing}

Additional data are available for this Article; details can be found in the appendix (p 20).

\section{Acknowledgments}

LM and AGR are supported by the NIHR Manchester Biomedical Research Centre.

\section{References}

1 Brenner H, Kloor M, Pox CP. Colorectal cancer. Lancet 2014; 383: $1490-502$.

2 Renehan AG, Malcomson L, Emsley R, et al. Watch-and-wait approach versus surgical resection after chemoradiotherapy for patients with rectal cancer (the OnCoRe project): a propensity-score matched cohort analysis. Lancet Oncol 2016; 17: $174-83$.

3 Breugom AJ, van de Velde CJ. Is it time for watchful waiting for rectal cancer? Lancet Oncol 2015; 16: 875-76.

4 Habr-Gama A, Gama-Rodrigues J, Sao Juliao GP, et al. Local recurrence after complete clinical response and watch and wait in rectal cancer after neoadjuvant chemoradiation: impact of salvage therapy on local disease control. Int J Radiat Oncol Biol Phys 2014; 88: 822-28.

5 Habr-Gama A, Perez RO, Nadalin W, et al. Operative versus nonoperative treatment for stage 0 distal rectal cancer following chemoradiation therapy: long-term results. Ann Surg 2004; 240: 711-17.

6 Habr-Gama A, Sabbaga J, Gama-Rodrigues J, et al. Watch and wait approach following extended neoadjuvant chemoradiation for distal rectal cancer: are we getting closer to anal cancer management? Dis Colon Rectum 2013; 56: 1109-17.

7 Maas M, Beets-Tan RG, Lambregts DM, et al. Wait-and-see policy for clinical complete responders after chemoradiation for rectal cancer. J Clin Oncol 2011; 29: 4633-40.

8 Martens MH, Maas M, Heijnen LA, et al. Long-term outcome of an organ preservation program after neoadjuvant treatment for rectal cancer. J Natl Cancer Inst 2016; 108: djw171.

9 Dossa F, Chesney TR, Acuna SA, Baxter NN. A watch-and-wait approach for locally advanced rectal cancer after a clinical complete response following neoadjuvant chemoradiation: a systematic review and meta-analysis. Lancet Gastroenterol Hepatol 2017; 2: 501-13.

10 Dattani M, Heald RJ, Goussous G, et al. Oncological and survival outcomes in watch and wait patients with a clinical complete response after neoadjuvant chemoradiotherapy for rectal cancer: a systematic review and pooled analysis. Ann Surg 2018; published online May 9. DOI:10.1097/SLA.0000000000002761.

11 van der Valk MJM, Hilling DE, Bastiaannet E, et al. Long-term outcomes of clinical complete responders after neoadjuvant treatment for rectal cancer in the International Watch \& Wait Database (IWWD): an international multicentre registry study. Lancet 2018; 391: 2537-45.

12 Burke DL, Ensor J, Riley RD. Meta-analysis using individual participant data: one-stage and two-stage approaches, and why they may differ. Stat Med 2017; 36: 855-75.

13 Riley RD, Lambert PC, Abo-Zaid G. Meta-analysis of individual participant data: rationale, conduct, and reporting. BMJ 2010; 340: c221.

14 Stewart LA, Clarke M, Rovers M, et al. Preferred reporting items for systematic review and meta-analyses of individual participant data: the PRISMA-IPD statement. JAMA 2015; 313: 1657-65. 
15 Heald RJ, Beets G, Carvalho C. Report from a consensus meeting: response to chemoradiotherapy in rectal cancer-predictor of cure and a crucial new choice for the patient: on behalf of the Champalimaud 2014 Faculty for 'Rectal cancer: when NOT to operate'. Colorectal Dis 2014; 16: 334-37.

16 Habr-Gama A, Perez RO, Wynn G, Marks J, Kessler H, Gama-Rodrigues J. Complete clinical response after neoadjuvant chemoradiation therapy for distal rectal cancer: characterization of clinical and endoscopic findings for standardization. Dis Colon Rectum 2010; 53: 1692-98.

17 Moga C, Guo B, Schopflocher D, Harstall C. Development of a quality appraisal tool for case series studies using a modified Delphi technique. Edmonton: Institute of Health Economics, 2012.

18 Renehan AG, Malcomson L, Emsley R. Watch-and-wait approach for rectal cancer: concepts of a subject-specific method. Lancet Gastroenterol Hepatol 2017; 2: 627.

19 Higgins JP, Thompson SG. Quantifying heterogeneity in a meta-analysis. Stat Med 2002; 21: 1539-58.

20 Hougaard P. Frailty models for survival data. Lifetime Data Anal 1995; 1: 255-73.

21 Wille-Jorgensen P, Syk I, Smedh K, et al. Effect of more vs less frequent follow-up testing on overall and colorectal cancer-specific mortality in patients with stage II or III colorectal cancer: the COLOFOL randomized clinical trial. JAMA 2018; 319: 2095-103.

22 Royston P, Sauerbrei W. A new approach to modelling interactions between treatment and continuous covariates in clinical trials by using fractional polynomials. Stat Med 2004; 23: 2509-25.

23 Pocock SJ, Ware JH. Translating statistical findings into plain English. Lancet 2009; 373: 1926-28.

24 MERCURY Study Group. Diagnostic accuracy of preoperative magnetic resonance imaging in predicting curative resection of rectal cancer: prospective observational study. BMJ 2006; 333: 779

25 Sterne JA, Sutton AJ, Ioannidis JP, et al. Recommendations for examining and interpreting funnel plot asymmetry in meta-analyses of randomised controlled trials. BMJ 2011; 343: d4002.

26 Ahmed I, Sutton AJ, Riley RD. Assessment of publication bias, selection bias, and unavailable data in meta-analyses using individual participant data: a database survey. BMJ 2012; 344: d7762.

27 Smith FM, Al-Amin A, Wright A, Berry J, Nicoll JJ, Sun Myint A. Contact radiotherapy boost in association with 'watch and wait' for rectal cancer: initial experience and outcomes from a shared programme between a district general hospital network and a regional oncology centre. Colorectal Dis 2016; 18: 861-70.
28 Lai CL, Lai MJ, Wu CC, Jao SW, Hsiao CW. Rectal cancer with complete clinical response after neoadjuvant chemoradiotherapy, surgery, or "watch and wait". Int J Colorectal Dis 2016; 31: 413-19.

29 Appelt AL, Ploen J, Harling H, et al. High-dose chemoradiotherapy and watchful waiting for distal rectal cancer: a prospective observational study. Lancet Oncol 2015; 16: 919-27.

30 Vaccaro CA, Yazyi FJ, Ojra Quintana G, et al. Locally advanced rectal cancer: preliminary results of rectal preservation after neoadjuvant chemoradiotherapy. Cir Esp 2016; 94: 274-79.

31 Dalton RS, Velineni R, Osborne ME, et al. A single-centr experience of chemoradiotherapy for rectal cancer: is there potential for nonoperative management? Colorectal Dis 2012; 14: 567-71.

32 Bitterman DS, Resende Salgado L, Moore HG, et al. Predictors of complete response and disease recurrence following chemoradiation for rectal cancer. Front Oncol 2015; 5: 286.

33 Araujo RO, Valadao M, Borges D, et al. Nonoperative management of rectal cancer after chemoradiation opposed to resection after complete clinical response. A comparative study. Eur J Surg Oncol 2015; 41: 1456-63.

34 Smith RK, Fry RD, Mahmoud NN, Paulson EC. Surveillance after neoadjuvant therapy in advanced rectal cancer with complete clinical response can have comparable outcomes to total mesorectal excision. Int J Colorectal Dis 2015; 30: 769-74.

35 Kong JC, Guerra GR, Warrier SK, Ramsay RG, Heriot AG. Outcome and salvage surgery following "watch and wait" for rectal cancer after neoadjuvant therapy: a systematic review. Dis Colon Rectum 2017; 60: 335-45.

36 Habr-Gama A, Sao Juliao GP, Gama-Rodrigues J, et al Baseline $\mathrm{T}$ classification predicts early tumor regrowth after nonoperative management in distal rectal cancer after extended neoadjuvant chemoradiation and initial complete clinical response. Dis Colon Rectum 2017; 60: 586-94.

37 Hupkens BJP, Maas M, Martens MH, et al. Organ preservation in rectal cancer after chemoradiation: should we extend the observation period in patients with a clinical near-complete response? Ann Surg Oncol 2018; 25: 197-203.

38 Sun Myint A, Smith FM, Gollins S, et al. Dose escalation using contact x-ray brachytherapy after external beam radiotherapy as nonsurgical treatment option for rectal cancer: outcomes from a single-center experience. Int J Radiat Oncol Biol Phys 2018; 100: 565-73.

39 Hupkens BJP, Martens MH, Stoot JH, et al. Quality of life in rectal cancer patients after chemoradiation: watch-and-wait policy versus standard resection-a matched-controlled study. Dis Colon Rectum 2017; 60: 1032-40. 